\title{
Study of Second Language Acquisition Efficiency based on SPOC Foreign Language Teaching Model
}

\author{
Liu Lei \\ School of Foreign Languages, Tianhe College of Guangdong Polytechnic Normal University, \\ Guangzhou510000, China. \\ 38650995@qq.com
}

Keywords: SPOC; foreign language teaching model; second language acquisition; statistical analysis; benefit evaluation

Abstract: In our country's foreign language teaching, the common teaching method is basically grammatical translation. In order to improve the efficiency of English teaching, an analytical model of second language acquisition efficiency based on SPOC foreign language teaching model is proposed. SPOC is another online curriculum model which has been widely popularized in the field of education since MOOC in recent years. Compared with traditional classroom teaching, it is more important in time and space. The content of teaching is more popular with teachers and students, the SPOC foreign language teaching mode is constructed, and the teaching mode reform is carried out in combination with the second language acquisition analysis method. The second language acquisition efficiency of foreign language teaching model is analyzed with statistical data analysis method, and the test statistical analysis model of second language acquisition in foreign language teaching is established, and the data analysis is carried out with SPSS software. Descriptive statistical analysis is used to evaluate the effectiveness of SPOC in foreign language teaching, and principal component analysis (PCA) is used to predict and analyze the efficiency of second language acquisition. The results show that the SPOC foreign language teaching model has a better effect, and the SPOC foreign language teaching model can effectively improve the quality of English teaching.

\section{Introduction}

With the advent of the "Internet plus" era, the integration of education and the Internet has become a new development trend in the field of education. Compared with the traditional classroom teaching, SPOC hybrid foreign language teaching has become the main body of teaching in time and space. There are great differences in teaching content. Under the SPOC teaching mode, hybrid teaching is the combination of tradition and modern under the background of big data. Abroad, hybrid teaching is mainly used in adult education and enterprise training and other fields ${ }^{[1]}$. In China, hybrid teaching research has just started, mainly in school education. With the increasingly frequent cross-cultural communication, colleges and universities in our country are also carrying out educational system reform and exploration. The traditional foreign language teaching mode can 
improve students' language level and examination-oriented level in a planned way, but the traditional classroom teaching is mostly limited to textbook knowledge. Because of the fixed space and teacher-centered teaching form, the teaching links are restricted, the students' interest in learning is difficult to improve, and the improvement of English achievement is not significant. This is also the problem that foreign language teaching has been paying close attention to and seeking a breakthrough in the reform. How to develop and utilize new teaching resources is the key to the reform of foreign language teaching. Therefore, the study of SPOC foreign language teaching mode plays an important role in improving the quality of foreign language teaching ${ }^{[2]}$.

For a long time, grammar translation is the most popular teaching method in foreign language teaching in China. Due to the generalization of grammar, the study of grammar rules has always been regarded as a means to lighten the burden of memory, and the study of grammar has naturally become the focus of foreign language teaching. However, a problem that cannot be ignored is that grammatical knowledge is only a kind of structure and the backbone of language. Therefore, this grammatic-centered teaching method can easily lead to the situation that the learner's knowledge system is only skeleton and has no substantial content ${ }^{[3]}$. This directly affects learners' communicative competence, which is the ultimate goal of foreign language teaching. Thus, in order to reduce the burden of learning language structure, rules have become a burden, a defect. SPOC foreign language teaching combines multimedia resources with classroom teaching, that is, in the context of big data. "Internet" and traditional teaching to achieve the time and space of complementarity. Students can watch microvideos repeatedly, set their own learning time, schedule and viewing mode, timely raise questions to teachers and students through SPOC platform or WeChat group, conduct online interaction, and stimulate some potential learning interests of students. The online test can also feedback the test results to the students in the first time, and improve the efficiency of learning by combining with the classroom learning for the content that is still not understood online. This paper analyzes the efficiency of SPOC foreign language teaching model and second language acquisition method, and analyzes the second language acquisition efficiency of foreign language teaching mode with statistical data analysis method. The model of test statistical analysis of second language acquisition in foreign language teaching is established. SPSS software is used to analyze the data and descriptive statistical analysis method is used to evaluate the benefits of SPOC foreign language teaching. Second language acquisition efficiency prediction and statistical analysis using principal component analysis (PCA). The results show that the SPOC foreign language teaching model has a better effect, and the SPOC foreign language teaching model can effectively improve the quality of English teaching. The results of empirical analysis demonstrate the superior performance of this method in improving the level of foreign language teaching ${ }^{[4]}$.

\section{Present situation of traditional Foreign language classroom teaching}

In the traditional English teaching mode, not only the traditional classroom teaching materials update slowly, the content is old, boring, teachers mostly use PPT or multimedia to attract students' interest, provide knowledge background, arouse students' interest in learning. And the traditional classroom time is limited, the teaching mainly takes the teaching material as the main body, the multimedia can only play the role of finishing the finishing point, but cannot carry on the long time teaching, therefore the traditional classroom returns to the goal of catching up the teaching progress, step by step ${ }^{[5]}$.

In space, the traditional classroom teaching class size is large, the learning attitude, the learning level difference is big, the teacher cannot carry on the effective interaction with each student, cannot satisfy the student individual demand, the teaching activity form is relatively monotonous, The 
learning atmosphere is rather dull, the learning effect presents the ladder shape development, which will inevitably lead to some students in the class learning state is not good, learning motivation is insufficient, the result that the study achievement drops.

In the teaching subject and teaching content, the traditional classroom is the typical spoon-feeding teaching, and the teacher is the main body. Due to the large number of students in the traditional classroom, the weak awareness of interaction between students and teachers in China, and the variety of written English test forms, teachers play a leading role in foreign language teaching and stay at the level of language knowledge, such as explaining vocabulary and grammar. Sentence pattern, text, not verbal level, that is, the meaning behind the language is not deeply excavated, and the language knowledge is not fully used for communication and communication.

\section{SPOC foreign language teaching model and second language acquisition theory}

SPOC is another online course model widely popularized by educational circles after MOOC in recent years. Compared with traditional classroom teaching, it is more popular with teachers and students in time and space, teaching subject and teaching content. This paper focuses on the analysis of the characteristics of SPOC foreign language teaching in the current reform and development, and points out that SPOC foreign language teaching can promote the deep integration of online education and traditional classroom teaching, thus infusing a new model into SPOC foreign language teaching. It can meet the individual learning needs of students, and then make students to truly achieve in-depth learning in a planned way.

Second language acquisition research is still the source of teaching advice, and we must be careful about the results, not mechanical application. In the course of teaching, the formulation of syllabus should conform to the law of language acquisition. As far as possible, we should choose "real language materials", such as real communication recording, television clips, news broadcasts, charts, photos, pictures, etc. Teachers cannot be regarded as merely a source of professional knowledge and a mentor. The role of teachers is not only to manage students and judge their learning, but also to assist students, participants in classroom activities, collaborators and psychological supporters. Teachers should speed up the learning process by encouraging learners to adopt the necessary strategies in the learning process. In terms of teaching content, in the process of foreign language teaching based on SPOC platform, teachers can arrange online teaching contents according to teaching needs, and students can adjust their own learning content according to their own preferences and needs. At the same time, on-line teaching is conducive to the interactive discussion between students, teachers and students, so that students can express their views, raise doubts, understand the important and difficult contents more comprehensively, and help teachers understand students' puzzles in a timely manner, so that they can answer questions and questions for students. It is beneficial to the balanced development of education. In the process of SPOC foreign language teaching, another physical content is offline teaching, that is classroom teaching ${ }^{[6]}$.

\section{Improving direction of foreign language teaching model}

\subsection{Improving the quantity and quality of input}

According to Krashen's second language acquisition theory, comprehensible language input is the key to language acquisition. That is to say, in the process of foreign language learning, the learners can reach the level of " $i$ " by including the language input of " $i+1$ " from their current language level ${ }^{[7]}$. Therefore, whether we can provide students with a large amount of comprehensible language input in foreign language teaching is the key to the success or failure of foreign language teaching. In order to make students more contact with comprehensible language 
input and improve learning efficiency, we must also increase the amount of language input. Therefore, it is necessary to make full use of teaching time and increase the amount of extracurricular listening and reading. At the same time, we should also pay attention to improving the quality of input, the teaching should adjust the difficulty of language input according to the students' characteristics and level, and the content should choose "real language material" to provide the right amount of language information and language knowledge. The students' existing language abilities is made full use, we can effectively deduce the relevant meanings and get a correct understanding.

\subsection{Attach importance to arousing students' enthusiasm for study}

With the emergence of cognitive psychology, people gradually realize that it is the inner development of the learners' own psychology and their mental ability that plays a decisive role in learning. Not objective stimulation and reinforcement, as behaviorist psychologists argue. Arousing students' enthusiasm is the key to improve teaching effect. Therefore, teachers should make great efforts to publicize the importance of English learning and the practicability of English as a tool to obtain information, strengthen the education of students' learning motivation, and let students change from "passive" learning to "active" learning. At the same time, we should take various ways to guide and stimulate students' enthusiasm for learning, improve their interest in learning, and build up their confidence in learning English well.

\subsection{Make clear the role and position of teachers}

Second language acquisition regards language learning as a process of creative construction and mistakes as an inevitable and positive part of the process. The study of second language acquisition classifies and characterizes some errors, which puts forward new requirements for teachers to decide the nature, type, countermeasures and attitude of learners. Teachers are not only the fountainheads and mentors of professional knowledge, but also the role of teachers not only in managing and judging their learning, but also in assisting students' learning, in the negotiation of classroom activities, in participants, collaborators and psychological supporters. Teachers can accelerate the learning process by encouraging learners to adopt necessary learning strategies.

\section{Statistical Analysis of second language acquisition efficiency based on SPOC Foreign language Teaching Model}

In order to quantitatively analyze the second language acquisition efficiency of SPOC foreign language teaching model, a statistical analysis model of test is constructed ${ }^{[8]}$. The evaluation model of second language acquisition efficiency is expressed as ARMA $(p, q)$ model by using linear correlation Gaussian process:

$$
x_{n}=\varphi_{0}+\sum_{i=1}^{p} \varphi_{i} x_{n-i}+\sum_{j=0}^{q} \theta_{j} \eta_{n-j}
$$

Where, $\left\{\eta_{i}\right\}$ is the mean value of 0 , and the independent codistributive random variable with variance $\sigma^{2}, \varphi_{0}, \varphi_{1}, \varphi_{2}, \cdots \varphi_{p}$ are called the autoregressive coefficients of effectiveness evaluation of SPOC foreign language teaching model, $\theta_{1}, \theta_{2}, \cdots \theta_{q}$ are the average coefficients of the improvement of students' achievement ${ }^{[9]}$. This paper constructs a statistical analysis model of second language acquisition in foreign language teaching, and defines the difference significance $S$ to evaluate the benefit of second language acquisition: 


$$
S=\frac{\left|\left\langle Q_{s}\right\rangle-Q_{0}\right|}{\sigma_{s}}
$$

Where, $\left\langle Q_{s}\right\rangle$ is the mean value of scores of $N$ group students using SPOC teaching model to improve their scores in foreign language learning, $\sigma_{s}$ indicates the standard deviation of $N$ batch foreign language achievement statistical analysis, that is, the standard deviation of $G$ batch foreign language achievement statistical analysis:

$$
\begin{gathered}
\left\langle Q_{s}\right\rangle=\frac{1}{N} \sum_{i=1}^{N} Q_{i} \\
\sigma_{s}=\sqrt{\frac{1}{N-1} \sum_{i=1}^{N}\left(Q_{i}-\left\langle Q_{s}\right\rangle\right)^{2}}
\end{gathered}
$$

The efficiency of second language acquisition (SLA) is predicted by using descriptive statistical analysis method and principal component analysis (PCA) method ${ }^{[10]}$, and Sigma test is used to evaluate the effectiveness of the original SPOC foreign language teaching. Let the probability distribution of $Q_{s}$ value of each substitution data be a common normal distribution, then:

$$
\begin{gathered}
p\left(Q_{s}\right)=\frac{1}{\sqrt{2 \pi} \sigma_{s}} \exp \left[-\frac{\left(Q_{s}-\left\langle Q_{s}\right\rangle\right)^{2}}{2 \sigma_{s}{ }^{2}}\right] \\
\int_{-\infty}^{\infty} p\left(Q_{s}\right) d Q_{s}=1
\end{gathered}
$$

Combining descriptive statistical analysis method and piecewise regression analysis method, the data analysis of benefit evaluation is carried out ${ }^{[11]}$, when satisfied:

$$
p\left(\left|Q_{0}-\left\langle Q_{s}\right\rangle\right|>Q_{c}\right) \leq 0.05
$$

Where, $z_{2}=-z_{1}=1.96$, then:

$$
\left|\left\langle Q_{s}\right\rangle-Q_{c}\right| / \sigma_{s}=z_{1}=1.96 \approx 2.00
$$

The criteria for assessing the benefits of second language acquisition are expressed as follows:

(I) $S \geq 2.00$, the false hypothesis with $95 \%$ probability does not hold, and the second language acquisition efficiency using the SPOC foreign language teaching mode is significantly improved.

(II) $S<2.00$, the hypothesis of hypocrisy is established, and the improvement of second language acquisition efficiency using SPOC foreign language teaching mode is not significant ${ }^{[12]}$.

The second language acquisition efficiency is identified by means test method. The mean test model is expressed as follows:

$$
\frac{d S_{k}(t)}{d t}=O_{k}(t)\left(P_{o s 1_{k}}+P_{o s 2_{k}}\right)+T_{k}(t) P_{t s k}-S_{k}(t) P_{s p k}-S_{k}(t) \beta_{a k}-S_{k}(t)\left(\beta_{u_{k}(t)}+\beta_{l_{k}(t)}\right)-S_{k}(t)\left(P_{s o 1_{k}}+P_{s o 2_{k}}\right)
$$

Where, $\Psi\left(d_{1}(t), d_{2}(t)\right)=\Psi+\Psi_{1}\left(d_{1}(t)\right)+\Psi_{2}\left(d_{2}(t)\right)$, the quantitative analysis of the second language acquisition efficiency of the foreign language teaching model is:

$$
\begin{gathered}
\Psi_{1}\left(d_{1}(t)\right)=\Psi+d_{1}(t) K\left(Z_{1}+Z_{2}+Z_{3}\right)^{-1} K^{T}+\left(h_{1}-d_{1}(t)\right)\left[W Z_{1}^{-1} W^{T}+L\left(Z_{2}+Z_{3}\right)^{-1} L^{T}\right] \\
\Psi_{2}\left(d_{2}(t)\right)=\Psi+\left(h_{2}-d_{2}(t)\right) L\left(Z_{2}+Z_{3}\right)^{-1} L^{T}+d_{2}(t) M^{T}\left(Z_{2}+Z_{3}\right)^{-1} M^{T}
\end{gathered}
$$

By using the confidence domain estimation method, the boundary conditions for the evaluation 
of second language acquisition benefits are defined as follows:

$$
P F=\left\{f(X)=\left(f_{1}(X), f_{2}(X), \ldots, f_{r}(X)\right) \mid X \in\left\{X^{*}\right\}\right\}
$$

On the basis of meeting the above constraints and combining with the training objectives of the SPOC foreign language teaching model, an evaluation model for the efficiency of second language acquisition is constructed as:

$$
\left.\max \left(H_{a c}\right) \boldsymbol{A}^{\left(\alpha_{1}, \cdots, \alpha_{m}\right)}\left(\boldsymbol{A}^{-1}\right)^{\left(\alpha_{1}^{-1}, \cdots, \alpha_{m}^{-1}\right)^{T}}=\left(\begin{array}{ccc}
\alpha_{1} a_{1,1} & \cdots & \alpha_{m} a_{1, m} \\
\vdots & \ddots & \vdots \\
\alpha_{1} a_{m, 1} & \cdots & \alpha_{m} a_{m, m}
\end{array}\right)\left(\begin{array}{ccc}
\alpha_{1}^{-1} t_{1,1} & \cdots & \alpha_{1}^{-1} t_{1, m} \\
\vdots & \ddots & \vdots \\
\alpha_{m}^{-1} t_{m, 1} & \cdots & \alpha_{m}^{-1} t_{m, m}
\end{array}\right)\left(x_{1}, \cdots, x_{m}\right)^{T}=\boldsymbol{E} I\left(a_{i}\right)\right)
$$

Under the condition of satisfying the boundary condition, the statistical quantity of the efficiency evaluation of second language acquisition is obtained to satisfy the $\boldsymbol{x}=\left(x_{1}, \cdots, x_{m}\right)^{T} \in \boldsymbol{G} \boldsymbol{F}\left(2^{n}\right)^{m}$. On the basis of the above analysis, a descriptive statistical analysis method is used to evaluate the effectiveness of SPOC in foreign language teaching. In order to improve foreign language teaching ability, principal component analysis (PCA) is used to predict and analyze the efficiency of second language acquisition (SLA).

\section{Empirical analysis and testing}

In order to compare the performance, SPSS14.0 software is used to analyze the data, and the effect of SPOC teaching model on the improvement of foreign language achievement in different classes is tested. By using the method of comparative analysis, three classes are compared and evaluated. Class 1 adopted SPOC mode of foreign language teaching, class 2 and class 3 did not adopt SPOC mode of foreign language teaching. After one year, the results of statistical average analysis of English scores are shown in Fig. 1, and the results of variance comparison are shown in Fig. 2. The results of the empirical analysis show that the grades of the classes using the SPOC teaching model are significantly higher than those of the other classes.

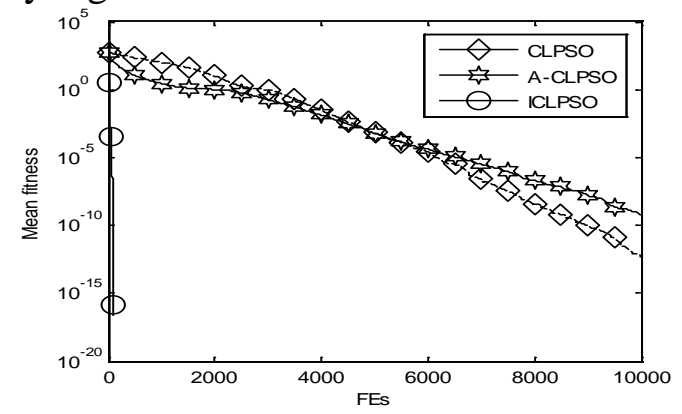

Fig. 1 Result of statistical average analysis of English achievement

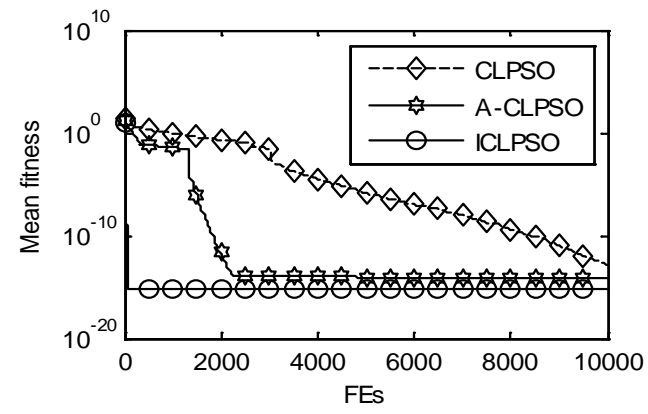

Fig. 2 Variance analysis results of English achievement 


\section{Conclusions}

In this paper, the SPOC teaching model and the second language acquisition theory are studied in order to improve the efficiency of English teaching. In this paper, an analytical model of second language acquisition efficiency based on SPOC foreign language teaching model is proposed. SPOC is another online curriculum model which has been widely popularized in the field of education since MOOC in recent years. Compared with traditional classroom teaching, it is more important in time and space. The content of teaching is more popular with teachers and students, the SPOC foreign language teaching mode is constructed, and the teaching mode reform is carried out in combination with the second language acquisition analysis method. The second language acquisition efficiency of foreign language teaching model is analyzed with statistical data analysis method, and the test statistical analysis model of second language acquisition in foreign language teaching is established, and the data analysis is carried out with SPSS software. Descriptive statistical analysis is used to evaluate the effectiveness of SPOC in foreign language teaching, and principal component analysis (PCA) is used to predict and analyze the efficiency of second language acquisition. The results show that the SPOC foreign language teaching model has a better effect, and the SPOC foreign language teaching model can effectively improve the quality of English teaching. This model has good application value in quantitative analysis and evaluation of foreign language teaching.

\section{References}

[1] ZHANG B Z, GUI X, HE T, et al. A novel recommender algorithm on fusion heterogeneous information network and rating matrix [J]. Journal of Computer Research and Development, 2014, 51(S2):69-75.

[2] LIN X Y, DAI L L, SHI S H, et al. Matrix factorization recommendation based on topic model[J]. Journal of Computer Applications, 2015, 35(S2):122-124.

[3] SLIMENI F, SCHEERS B, NIR V L, et al. Learning multi-channel power allocation against smart jammer in cognitive radio networks[C]//Proceedings of the 2016 International Conference on Military Communications and Information systems. Piscataway, NJ:IEEE, 2016:1-7.

[4] LIU Z X, LEI L, ZHANG N B, et al. Joint beamforming and power optimization with iterative user clustering for MISO-NOMA systems[J]. IEEE Access, 2017, 23(99):1-11.

[5] ALI M S, TABASSUM H, HOSSAIN E. Dynamic user clustering and power allocation for uplink and downlink Non-Orthogonal Multiple Access (NOMA) systems[J]. IEEE Access, 2016, 4:6325-6343.

[6] KIM B, CHUNG W, LIM S, et al. Uplink NOMA with multi-antenna[C]//Proceedings of the 2015 IEEE 81st Vehicular Technology Conference. Piscataway, NJ:IEEE, 2015:1-5.

[7] JIANG Y Z, CHUNG F L, WANG S T, et al. Collaborative fuzzy clustering from multiple weighted views[J]. IEEE Transactions on Cybernetics, 2015, 45(4): 688-701.

[8] BI Anqi, DONG Aimei, and WANG Shitong. A dynamic data stream clustering algorithm based on probability and exemplar [J]. Journal of Computer Research and Development, 2016, 53(5): 1029-1042.)

[9] HUANG Hongwei, GE Xiaotian, CHEN Xuansong. Density clustering method based on complex learning classification system[J]. Journal of Computer Applications, 2017, 37(11): 3207-3211.

[10]JI Yugang, LI Yitong, SHI Chuan. Aspect rating prediction based on heterogeneous network and topic model[J]. Journal of Computer Applications, 2017, 37(11): 3201-3206.

[11]ZHANG B Z, GUI X, HE T, et al. A novel recommender algorithm on fusion heterogeneous information network and rating matrix[J]. Journal of Computer Research and Development, 2014, 51(S2):69-75.

[12]LIN X Y, DAI L L, SHI S H, et al. Matrix factorization recommendation based on topic model[J]. Journal of Computer Applications, 2015, 35(S2):122-124. 